University of Wollongong

Research Online

Faculty of Engineering and Information

Faculty of Engineering and Information

Sciences - Papers: Part A

Sciences

$1-1-2012$

Discussion of "Depth-averaged shear stress and velocity in open-channel flows" by Shu-Qing Yang

M Sterling

University of Birmingham

Xiannan Tang

University of Birmingham

Follow this and additional works at: https://ro.uow.edu.au/eispapers

Part of the Engineering Commons, and the Science and Technology Studies Commons

Research Online is the open access institutional repository for the University of Wollongong. For further information contact the UOW Library: research-pubs@uow.edu.au 


\title{
Discussion of "Depth-averaged shear stress and velocity in open-channel flows" by Shu-Qing Yang
}

\begin{abstract}
The discussers thank the author for writing an informative and thought-provoking paper. Predicting the lateral distribution of boundary shear stress in open-channel flows is an intractable issue, and any theoretical work in this area is to be welcomed. The purpose of this discussion is twofold: first, to compare the analysis developed by the author to experimental data; and second, to seek clarification on several areas of potential confusion, which may be due to typographical errors.
\end{abstract}

\section{Keywords}

shu, flows, channel, open, yang, velocity, qing, stress, shear, averaged, depth, discussion

Disciplines

Engineering | Science and Technology Studies

\section{Publication Details}

Sterling, M. \& Tang, X. (2012). Discussion of "Depth-averaged shear stress and velocity in open-channel flows" by Shu-Qing Yang. Journal of Hydraulic Engineering, 138 (10), 912-913. 


\section{Discussion of "Depth-Averaged Shear Stress and Velocity in Open-Channel Flows" by Shu-Qing Yang}

November 2010, Vol. 136, No. 11, pp. 952-958.

DOI: 10.1061/(ASCE)HY.1943-7900.0000271

\author{
M. Sterling ${ }^{1}$ and X. Tang ${ }^{2}$ \\ ${ }^{1}$ Reader in Fluid Dynamics, School of Civil Engineering, Univ. of \\ Birmingham, Edgbaston, Birmingham, UK (corresponding author). \\ E-mail: masayuki@-civil.cst.nihon-u.ac.jp \\ ${ }^{2}$ Univ. Research Fellow, School of Civil Engineering, Univ. of \\ Birmingham, Edgbaston, Birmingham, UK.
}

The discussers thank the author for writing an informative and thought-provoking paper. Predicting the lateral distribution of boundary shear stress in open-channel flows is an intractable issue, and any theoretical work in this area is to be welcomed. The purpose of this discussion is twofold: first, to compare the analysis developed by the author to experimental data; and second, to seek clarification on several areas of potential confusion, which may be due to typographical errors.

This discussion will focus on uniform flow in a circular pipe running part full because this is one of the examples used by the author (Fig. 9 in the original paper); however, the same general principles can be extended to a channel of any shape. The discussers find it surprising that the author should develop expressions for boundary shear stress but not compare them to experimental data, particularly because the experimental data were illustrated in one of the original references (Knight and Sterling 2000). For the sake of completeness and to fully explore the applicability of the author's model, this comparison is presented in Figs. 1 and 2. In Figs. 1 and 2, the vertical axis represents the local boundary shear stress normalized by the global value $(\rho g R S$, where $\rho$ is the density of water, $g$ is the acceleration due to gravity, $R$ is the hydraulic radius, and $S$ is the energy slope) and the horizontal axis represents the relative distance along the wetted perimeter, i.e., $\theta /(2 \alpha)$ using Yang's notation. However, as discussed in the following, it appears that $\theta$ is incorrectly labeled in Fig. 9 of Yang's paper; hence, to avoid confusion, a new term will be adopted: $P d=s / P$, where $s$ is the distance along the boundary starting at the left bank at the free surface (looking downstream) and $P$ is the total length of the wetted perimeter.

Figs. 1 and 2 illustrate that there appear to be noticeable differences between the predicted and measured distributions. In Fig. 1, Yang's method overpredicts the magnitude of the normalized shear stress over the central region of the wetted perimeter and underpredicts close to the edge of the channel, whereas the opposite is shown in Fig. 2. Additionally, the perturbations in normalized shear stress arising as a result of the influence of secondary flow are not present in the simulations but can be observed in the experimental data. This is perhaps not too surprising because the effects of secondary flow are not taken into account in Yang's method. Also apparent in Figs. 1 and 2 are the predicted values of zero boundary shear stress at $P d=0$ and 1 -physically, such values cannot occur in practice. With respect to Fig. 2, the discussers suspect that Yang's method is not applicable when $h / D>0.5$ (and seek clarification of this), however, the experimental data are sufficiently close to enable a qualitative understanding to be obtained (i.e., the error in relative depth is $1.2 \%$ ).

As outlined in Knight and Sterling (2000), it is often beneficial to be able to calculate the "apparent shear stress" on any vertical within the channel. This is also acknowledged by Yang, who provides an analytical equation enabling this variable to be calculated [Eq. (14)]. However, the qualitative comparison undertaken only considers one set of experimental data. To extend this comparison and provide a quantitative assessment, the absolute difference between the predicted and experimental data is presented in Fig. 3 for the two cases outlined in Figs. 1 and 2 (data relating to half of the channel is shown due to the symmetrical nature of both the experimental and predicted data about the centerline).

Fig. 3 shows that when $h / D \sim 0.5$, the absolute difference is reasonably large $(0.15)$ over a large part of the boundary. The discussers suspect that this may be due to the contribution that secondary flows make to the measured boundary shear stress, which is not taken into account in Yang's method. However, the

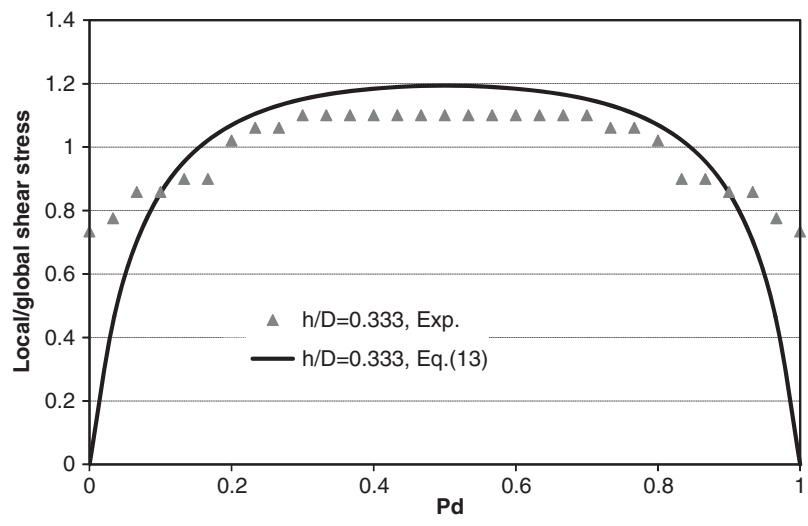

Fig. 1. Distribution of normalized boundary shear stress for subcritical flow with $h / D=0.333$ with respect to relative wetted perimeter distance (data from Knight and Sterling 2000)

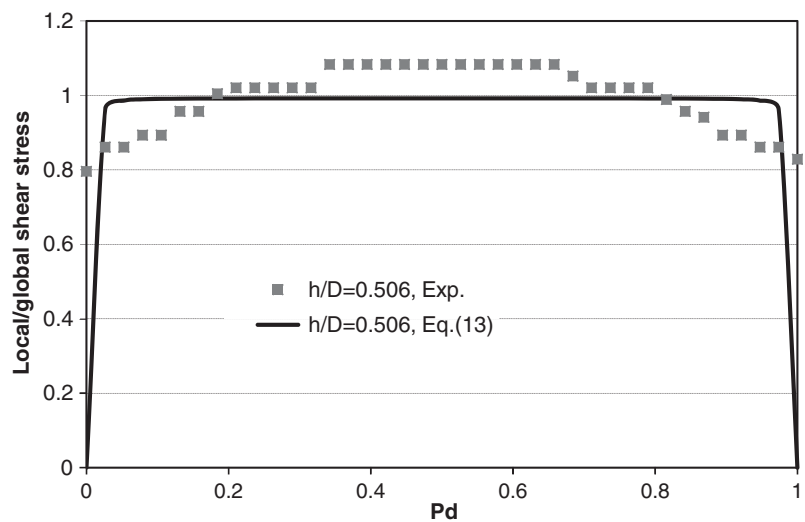

Fig. 2. Distribution of normalized boundary shear stress for subcritical flow with $h / D=0.506$ with respect to relative wetted perimeter distance (data from Knight and Sterling 2000) 


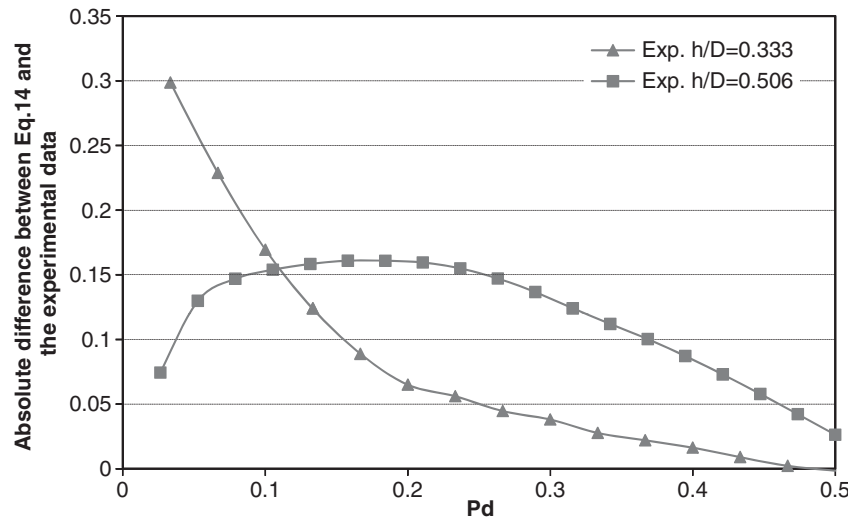

Fig. 3. Absolute difference in apparent shear stress distributions with respect to relative wetted perimeter distance

differences illustrated in Fig. 3 are smaller than one may expect from Figs. 1 and 2.

The second part of the discussion relates to the clarification of a number of small points.

1. In the caption of Fig. 2 of the original paper, Eq. (17) does not exist. Should this be Eq. (14)?

2. The discussers suspect that the caption of Fig. 7 is incorrect and should refer to the work of Knight and Sterling (2000).

3. In the section entitled "Open-Channel Flows," is the equation number in the second line correct, i.e., should it be Eq. (13) rather than Eq. (12)?

4. Is the correct equation referred to in the captions of Figs. 5 and 6 ?

5. Fig. 5(a) appears to suggest that $u / u \max =0$. Is this a typographical error?

6. Should $\theta$ in Fig. 9 correspond to the angle between the line going through c' from the center and the centerline of the channel?

7. Is $\theta=\sin ^{-1}(\sin \alpha-z / r)$, as opposed to the expression shown on page 957 , i.e., $\sin ^{-1}[\sin \alpha(-z / r)]$ ?

8. The discussers suspect that for the case of a circular channel, Eqs. (13) and (14) are only valid for $h / D<0.5$. Clarification would be appreciated.

\section{Reference}

Knight, D. W., and Sterling, M. (2000). "Boundary shear in circular pipes running partially full.” J. Hydraul. Eng., 126(4), 263-275.

\section{Discussion of "Depth-Averaged Shear Stress and Velocity in Open-Channel Flows" by Shu-Qing Yang}

November 2010, Vol. 136, No. 11, pp. 952-958.

DOI: 10.1061/(ASCE)HY.1943-7900.0000271

\section{Anatoly Kusher, Ph.D.}

${ }^{1}$ Head of Laboratory of Hydrometry, All Russia Scientific Research Institute of Hydraulic Engineering and Land Reclamation, 127550, Moscow, ul. B. Academicheskaya, 44, Russia. E-mail: econg@ pochtamt.ru
Eq. (1) of the original paper shows that a derivative $\Delta A / \Delta p$ (a ratio of elementary area between two normal lines to the elementary wetted perimeter) is equal to

$$
\frac{\Delta A}{\Delta p}=\frac{\tau_{b}(z)}{\rho g S}=L(z)
$$

where $\tau_{b}(z)$ is a local boundary shear stress.

In the trapezoidal canal values, $L(z)$ are equal to lengths of the normal lines from a point $z$ on the wall or the bed to the free surface line or to the bisector line of the trapezoid interior angle. The four parts of the trapezoid canal cross section divided according to the original method [Eq. (15)] are shown in Fig. 1. Function $L(z)$ has a piecewise-linear structure with a variable sign of derivative for any trapezoidal cross section (Fig. 2).

A local boundary shear stress $\tau_{b}(z)=\rho g S L(z)$, a local shear velocity $u_{*(z)}=\left(\tau_{b}(z) / \rho\right)^{0.5}$, a parameter $f$, and a local velocity profile $u(y, z)$ in Eq. (6) are nonmonotonic functions with sharp depression around the joint of the bed and the side wall. The result is the same for smooth and rough walls. The calculated velocity profile is shown in Fig. 3. The profile shape is not physically correct.

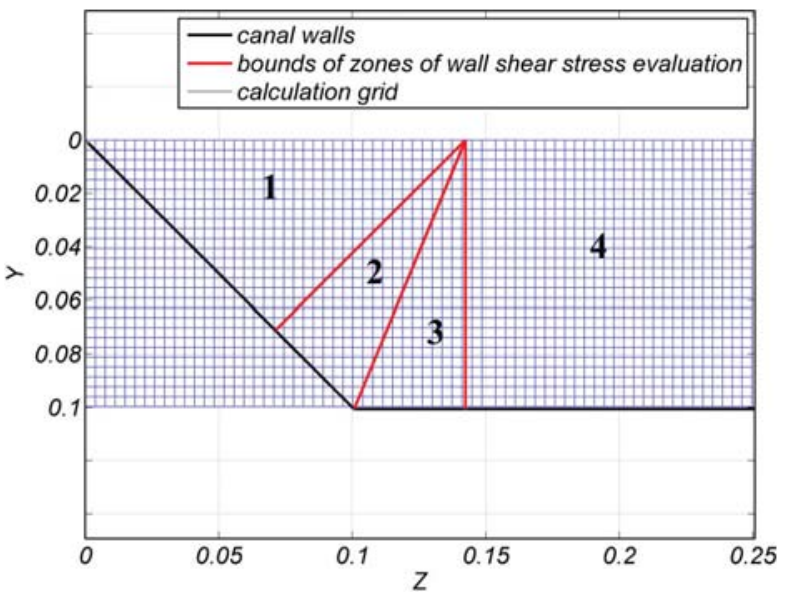

Fig. 1. Parts of trapezoid canal cross section divided according to original method

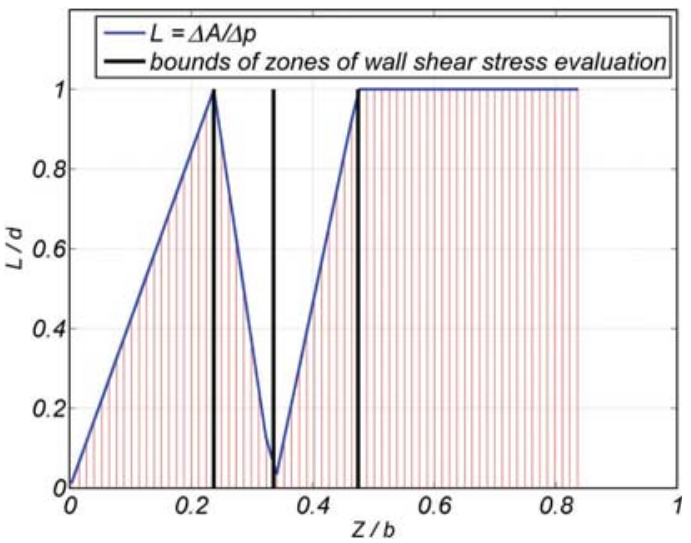

Fig. 2. Change of derivative $\Delta A / \Delta p$ along perimeter of trapezoidal canal [Eq. (15)] 


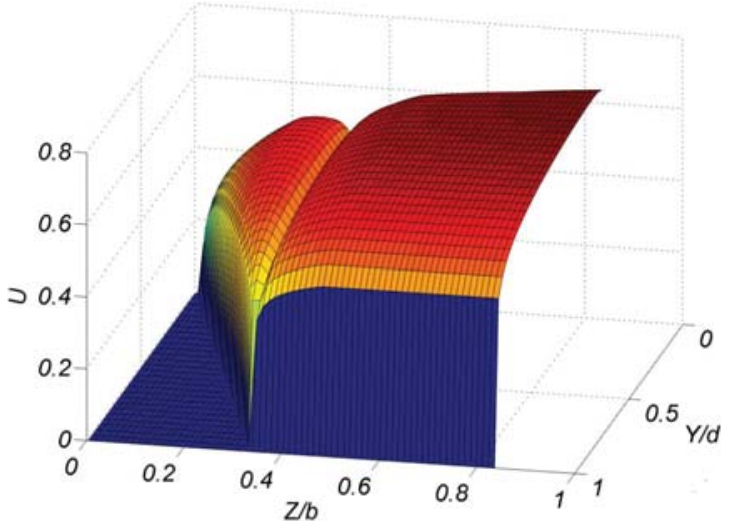

Fig. 3. Velocity profile calculated using Eq. (6) in original paper

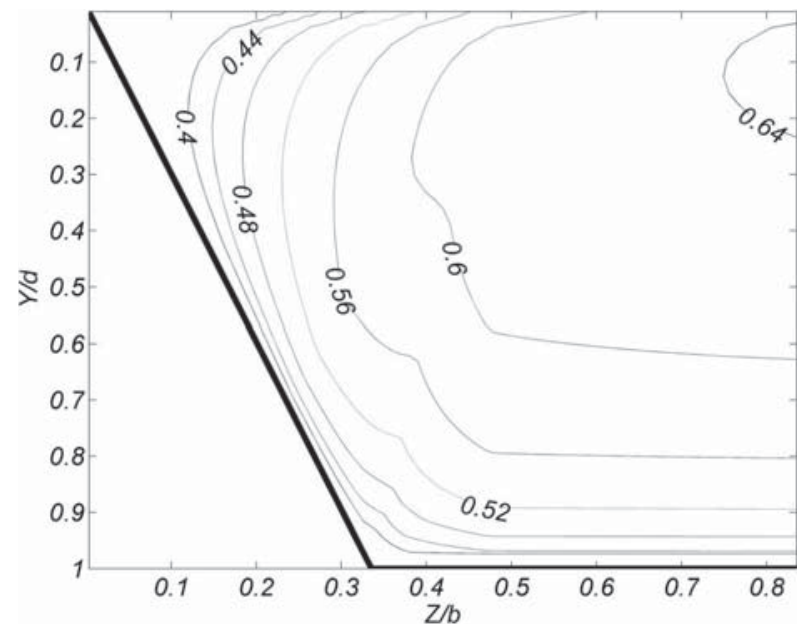

Fig. 4. Flow profile found by computing velocities along normal lines to wall boundaries

As noted in the paper, a velocity profile may be found by calculating velocities along normal lines to boundaries. The discusser tried to calculate a velocity profile numerically. First, velocity values were found along normal lines by the use of the local shear stress [Eq. (15)], and then the total profile was calculated by interpolating data into the nodes of the rectangular grid (Fig. 4). Except for the corner region, the computed profile is closer to the experimental data than was found by the use of Eq. (6) in the original paper. Therefore, further research is needed to calculate the local boundary shear stress in canal corner regions.

\section{Closure to "Depth-Averaged Shear Stress and Velocity in Open-Channel Flows" by Shu-Qing Yang}

November 2010, Vol. 136, No. 11, pp. 952-958.

DOI: $10.1061 /(A S C E) H Y .1943-7900.0000271$

\section{Shu-Qing Yang, M.ASCE${ }^{1}$}

${ }^{1}$ Associate Professor, School Civil, Mining and Environmental Engineering, Univ. of Wollongong, NSW 2522, Australia. E-mail shuqing@uow.edu.au

\section{Reply to Discussion by M. Sterling and X. Tang}

The writer would like to thank the discussers for their valuable comments. Two prominent researchers have done substantial and influential work in this area. The work of Knight and Sterling (2000) was not compared with the derived equation of boundary shear stress distribution because of the length requirement of the original paper. The article was initially submitted as a full-length paper, but it was requested that it be a technical note, so all comparisons of boundary shear stress distribution were removed. The writer agrees with the discussers that the discrepancy shown in Figs. 1 and 2 is because "the effects of secondary flow are not taken into account in Yang's method." It is correct that Yang's method is invalid when $h / D>0.5$, thus Eq. (13) should not be applied to Fig. 2, or using $d=r$, Eq. (13) in the note becomes a horizontal line in Fig. 2.

The writer disagrees that "zero boundary shear stress at $P d=0$ and 1 cannot occur in practice." The channel in Fig. 1 can be simplified or approximated as a trapezoidal channel, for which Ghosh and Roy (1970) measured the boundary shear stress and found that "the wall shear near the free surface is maximum in a rectangular channel but it suddenly drops to almost zero in a trapezoidal channel, and the magnitude of zero shear remains fairly unaffected by any change in the side slope." Obviously, this observation supports Yang's method. Generally, the local boundary shear stress near the free surface on an inclined wall must be zero, but it is very hard to measure.

The secondary currents are detectable from the discrepancy between the measured boundary shear stress distribution and Yang's prediction, because the secondary flow toward the boundary enhances the local boundary shear stress, and the secondary flow apart away from the boundary lessens the local boundary shear stress. Hence from Figs. 1 and 2 in this discussion, one can infer the existence of the secondary current and its flow direction. Furthermore, once the quantitative relationship between the secondary flow and the difference of measured and predicted local boundary shear stress is established, one is able to determine the quantity of secondary flow in the boundary region; or if the secondary flow is accurately predicted, together with Yang's method, one is able to determine the boundary shear stress with high accuracy.

The reasonably large difference shown in Fig. 3 can be attributed to the omission of secondary currents, but a significant part may have been caused by measurement errors, especially at the intersection of the boundary and the free surface. As mentioned previously, the zero boundary shear stress at the intersection of the free surface and the solid wall was not measured by the experimenters, thus it is hard to be certain that the effect of secondary currents is a sole reason. In the writer's opinion, the influence of secondary currents on the apparent shear stress is not as significant as that on the boundary shear stress because its effect is weakened after the depth integration.

The writer appreciates the discussers spotting the typographic errors and regrets these errors. The equation in the captions of Figs. 5-7 should be Eq. (6), not Eq. (25), and in Fig. 5(a) the text should be $u / u \max =0.7$, not 0 . Both Eqs. (13) and (4) are valid only for $h / D<0.5$. The caption of Fig. 7 is the work of Knight and Sterling (2000): the writer is sorry for the mistake.

\section{Reply to Discussion by Anatoly Kusher}

The writer would like to express his sincere appreciation to the discusser for his in-depth investigation on the topic. The confusion was primarily caused by the reduction from a paper to a technical note; thus, some useful information was lost. 
In the original paper, the vertical velocity profile is discussed, not the profile along the wall normal lines, even though Eq. (6) theoretically expresses the velocity distribution along a normal line of boundary, not the vertical line (Yang et al. 2004). In Eq. (6), the first term on the right-hand side expresses the influence of the lower boundary, and the second term expresses the effect of the upper boundary. The influence of the sidewall is included in $f$ and $\alpha_{1}$. In this note, the writer calculated the velocity distribution along verticals at $z / h=0.05,0.1$, $0.15,0.2$ to 1.6 with the interval of 0.1 , and the overall shear velocity $u_{*}=1.64 \mathrm{~cm} / \mathrm{s}$, and $u_{\max }=37.82 \mathrm{~cm} / \mathrm{s}$. Based on the calculated velocity, the iso-velos were drawn and shown in Fig. 6.

In the discusser's Fig. 3, the velocity becomes very small along the bisector line as the "function with sharp depression around the joint of the bed and the wall." As mentioned, Fig. 6(b) in the original paper was calculated using the vertical lines, not the boundary normal lines, but the discusser used the boundary normal lines for the velocity calculation.

If the boundary normal lines are used for calculation, for a smooth boundary Eq. (6) can be rewritten in the following way:

$$
\frac{u}{u_{* o}}=\left[2.5 \ln \frac{u_{*(z)} l_{n}}{\nu}+B\right]+2.5 \alpha_{1} \ln \left(1-\frac{l_{n}}{L_{n}}\right)
$$

where $u_{* 0}=$ global overall shear velocity; $u_{*(\mathrm{z})}=$ local shear velocity; $l_{n}=$ normal distance to the boundary from a discussed point; $L_{n}=$ distance from the boundary to the free surface; $B=$ 5.5 for the verticals from the bed, but it is variable in the sidewall region to meet the condition of velocity continuity, i.e., along the division line or bisector, the velocity must be the same, either using the verticals, or sidewall normal lines (Yang et al. 2004). The writer does not use Eq. $(1 a)$ in the original paper because $L_{n}$ in Eq. $(1 a)$ is hard to define, as the second term expresses the free surface effect.

The shear velocities on both sides of Eq. (1a) or Eq. (6) (original paper) are different. Using this definition, the effect of "sharp depression" could be eliminated. Although the writer never uses Eq. (1a) to check whether the "sharp depression" exists in a trapezoidal channel, the writer did this for a rectangular channel (a special trapezoidal channel) using Eq. (1a) without the dip term, and the results show that the calculated velocity agrees with the measured data (Yang et al. 2005), even better than some numerical models (Yang 2005). No sharp depression appears along the division line. Thus, the "physically not correct" velocity distribution obtained by the discusser was not caused by the model itself but by misinterpretation.

\section{References}

Ghosh, S. N., and Roy, N. (1970). "Boundary shear distribution in open channel flow." J. Hydraul. Div., 96(4), 967-994.

Knight, D. W., and Sterling, M. (2000). "Boundary shear in circular pipes running partially full." J. Hydraul. Eng., 126(4), 263-275.

Yang, S. Q. (2005). "Interactions of boundary shear stress, secondary currents and velocity." Fluid Dynam. Res., 36(3), 121-136.

Yang, S. Q., Lim, S. Y., and McCorquodale, J. A. (2005). "Investigation of near wall velocity in 3-D smooth channel flows." J. Hydr. Res., 43(2), 149-157.

Yang, S. Q., Yu, J., and Wang, Y. Z. (2004). "Estimation of diffusion coefficients, lateral shear stress, and velocity in open channels with complex geometry." Water Resour. Res. AGU, 40(5), W05202.

\section{Discussion of "Analysis of Dynamic Wave Model for Unsteady Flow in an Open Channel" by Maurizio Venutelli}

September 2011, Vol. 137, No. 9, pp. 1072-1078.

DOI: $10.1061 /(A S C E) H Y .1943-7900.0000405$

\section{Cristiana Di Cristo1; Michele lervolino²; and}

Andrea Vacca ${ }^{3}$

${ }^{1}$ Assistant Professor, Dipartimento di Ingegneria Civile e Meccanica, Università di Cassino e del Lazio Meridionale, Via Di Biasio 43, 03043 Cassino (FR), Italy (corresponding author). E-mail: dicristo@unicas.it

${ }^{2}$ Assistant Professor, Dipartimento di Ingegneria Civile, Seconda Università di Napoli, Via Roma 29, 81031 Aversa (CE), Italy. E-mail: michele.iervolino@unina2.it

${ }^{3}$ Associate Professor, Dipartimento di Ingegneria Civile, Seconda Università di Napoli, Via Roma 29, 81031 Aversa (CE), Italy. E-mail: vacca@unina.it

In the original paper, the analytical expressions of phase and group speeds and wave amplitude have been derived by studying the linearized shallow-water equations (SWEs). The author's results, accounting for both channel $\left(S_{0}\right)$ and friction $\left(S_{f}\right)$ slopes, allow assessing convergence and accuracy of numerical schemes commonly used to compute clear-water flows in the complete turbulent regime, assuming a constant friction parameter $\eta$.

However, the shallow-water model is employed in several contexts in which the friction parameter cannot be assumed as a constant; for instance, clear-water flows in regimes different from the complete turbulent one (Yen 2002), free surface flows of mud (Engelund and Wan 1984), power-law fluids (Pascal 2006; Pascal and D'Alessio 2007), and dense particulates (Forterre and Pouliquen 2003). The knowledge of the analytical expression of phase and group speeds valid for the preceding processes would be useful for assessing the quality of the schemes employed for the numerical simulations.

The present discussion, following the procedure used in Di Cristo et al. (2009, 2010, 2012), generalizes the results of the original paper to the case in which the friction parameter is expressed by a smooth function of flow depth $(h)$ and velocity $(u)$.

As an application, the clear-water flow in the transitional regime is considered. The resistance coefficient $\lambda=8 g \eta$ is evaluated through a Colebrook-White type formula

$$
\frac{1}{\sqrt{\lambda}}=a \ln \left(\frac{d}{\mathrm{R} \sqrt{\lambda}}+e \frac{\varepsilon}{h}\right)
$$

in which $\varepsilon=$ sand equivalent roughness; $\mathrm{R}=u h / \nu$ is the Reynolds number, with $\nu$ the kinematic viscosity; and $a, d$, $e=$ dimensionless experimental coefficients.

In the following, the notation of the original paper is used. Assuming that the friction slope, $S_{f}$, is still expressed by $S_{f}=$ $\eta u|u| / h^{2 m}$ (wide channel), but with $\eta$ a smooth function of the velocity and the flow depth, i.e., $\eta=\eta(u, h)$, the linearized expression of the friction slope may be obtained from the Taylor expansion of $S_{f}$ around the uniform base state and neglecting the higher-order terms (Di Cristo et al. 2010). With the subscript $0=$ uniform base state flow condition and the superscript $I=$ perturbed variables, the linearized expression of the friction slope can be written as

$$
S_{f} \approx S_{0}\left[1-(2 m-B) h^{\prime} / h_{0}+(2+A) u^{\prime} / u_{0}\right]
$$

in which the coefficients $A$ and $B$, accounting for the dependence of the friction parameter $\eta$ on $h$ and $u$, are defined as 


$$
A=\frac{u_{0}}{\eta_{0}}\left[\frac{\partial \eta}{\partial u}\right]_{0} \quad B=\frac{h_{0}}{\eta_{0}}\left[\frac{\partial \eta}{\partial h}\right]_{0}
$$

Therefore, the dispersion relation, Eq. (7) of the original paper, becomes

$$
\begin{aligned}
\omega= & \kappa u_{0} \pm \sqrt{\frac{1}{2}\left[|z|+\kappa^{2} c^{2}-\frac{r^{2}}{4}\left(\frac{2+A}{2}\right)^{2}\right]} \\
& \pm i \sqrt{\frac{1}{2}\left[|z|-\kappa^{2} c^{2}+\frac{r^{2}}{4}\left(\frac{2+A}{2}\right)^{2}\right]}-i \frac{r}{2}\left(\frac{2+A}{2}\right)
\end{aligned}
$$

with

$$
|z|=\sqrt{\left[\kappa^{2} c^{2}-\frac{r^{2}}{4}\left(\frac{2+A}{2}\right)^{2}\right]^{2}+\left[\kappa u_{0} r\left(m-\frac{B}{2}\right)\right]^{2}}
$$

Indeed, phase and group speeds may be easily deduced starting from their definitions [i.e., Eqs. (8)-(10) of the original paper] with $\omega=\omega(\kappa)$ given by Eq. (4). Using the dimensionless variables considered in the original paper, the nondimensional phase and group speeds become

$$
\hat{v}_{p}=b \mathrm{~F}_{0} \pm \frac{1}{p \sqrt{2}} \sqrt{\alpha_{1}}
$$

and

$$
\hat{v}_{g}=b \mathrm{~F}_{0} \pm \frac{p b^{2}\left[2 \alpha_{1}+m^{2} D_{f}^{2} \mathrm{~F}_{0}^{2}(1-B)^{2}\right]}{2 \sqrt{2}|\hat{z}| \sqrt{\alpha_{1}}}
$$

with

$$
\alpha_{1}=|\hat{z}|+p^{2} b^{2}-\frac{D_{f}^{2}(2+A)^{2}}{16}
$$

and

$$
|\hat{z}|=\sqrt{\left[p^{2} b^{2}-\frac{D_{f}^{2}(2+A)^{2}}{16}\right]^{2}+\left[m b p D_{f} \mathrm{~F}_{0}(1-B)\right]^{2}}
$$

Eqs. (6) and (7), generalizing Eqs. (13) and (14) of the original paper, provide the analytical expressions of phase and group speeds

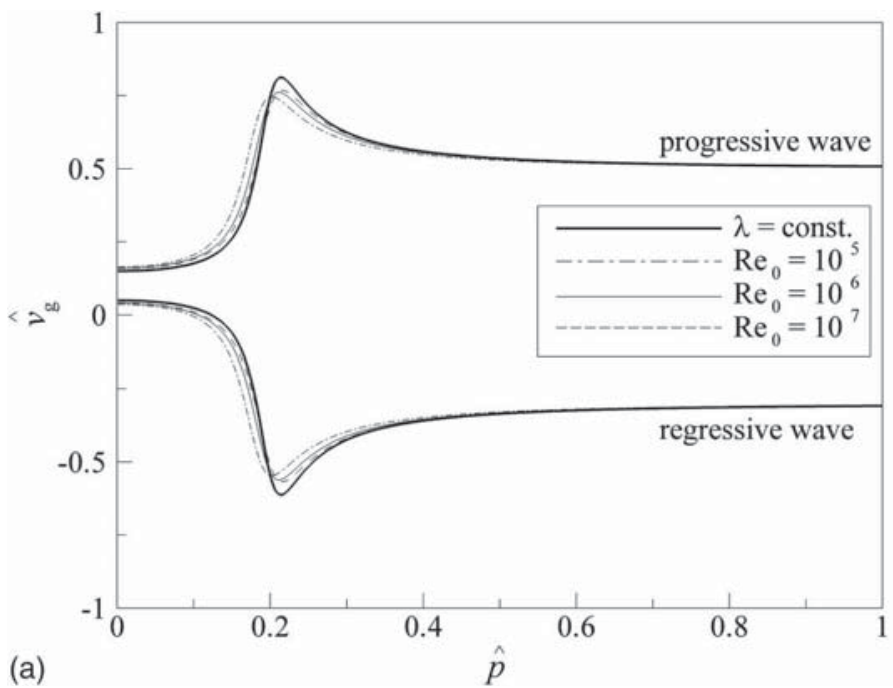

for a large class of resistance laws in which the friction parameter smoothly depends on the velocity and flow depth. For instance, they may be used to analyze the performance of numerical schemes for SWEs in the turbulent regime. In such a case, evaluating the friction parameter in the $S_{f}$ expression in terms of the resistance coefficient $(\eta=\lambda / 8 g)$, and assuming $m=1 / 2$ and expressing $\lambda$ through Eq. (1), the $A$ and $B$ coefficients read

$$
\begin{gathered}
A=\frac{2 a d \sqrt{\lambda_{0}}}{e \mathrm{R}_{0} \varepsilon_{0} \sqrt{\lambda_{0}}-a d \sqrt{\lambda_{0}}+d} \\
B=\frac{2 a\left(\lambda_{0} e \mathrm{R}_{0} \varepsilon_{0}+d \sqrt{\lambda_{0}}\right)}{e \mathrm{R}_{0} \varepsilon_{0} \sqrt{\lambda_{0}}-a d \sqrt{\lambda_{0}}+d}
\end{gathered}
$$

in which $\varepsilon_{0}=\varepsilon / h_{0}$ (relative roughness); $\mathrm{R}_{0}=u_{0} h_{0} / \nu$ (Reynolds number); and $\lambda_{0}=$ resistance coefficient of the base uniform flow.

For given values of the Courant number, $C_{r}$, and of the dimensionless friction parameter, $D_{f}$, the phase and group speeds depend not only on the dimensionless wavelength and the Froude numbers, as in the constant friction coefficient case, but also on the relative roughness and the Reynolds number. Figs. 1 and 2 enlighten the influence of both Reynolds number and relative roughness on the dimensionless group speed for both progressive and regressive waves, assuming $C_{r}=0.5$ and $D_{f}=0.5$. In particular, Fig. 1 shows for both subcritical $\left(F_{0}=0.25\right)$ and supercritical $\left(F_{0}=2.5\right)$ conditions, the influence of Reynolds number for a fixed value of relative roughness $\left(\varepsilon_{0}=10^{-4}\right)$, whereas Fig. 2 depicts the influence of relative roughness for a fixed value of Reynolds number $\left(\mathrm{R}_{0}=10^{5}\right)$. For the sake of comparison, the curves corresponding to the constant resistant coefficient assumption (i.e., $A=B=0$ ) are also plotted in the figures. The values of the dimensionless experimental coefficients $a, d, e$ for the case under investigation have been assumed as follows: $a=-2.03 / \ln (10) ; d=0.425$; and $e=1 / 10.95$ (Rouse 1959).

Figs. 1 and 2 suggest that, independently of the Froude number, the effect of the Reynolds number and relative roughness is approximately the same for progressive and regressive waves. In contrast, while for hypercritical conditions both Reynolds number and relative roughness only marginally influence the group speed, in hypocritical conditions the influence should be considered. In all cases, differences are observed with respect to the curve obtained assuming the resistance coefficient as a constant.

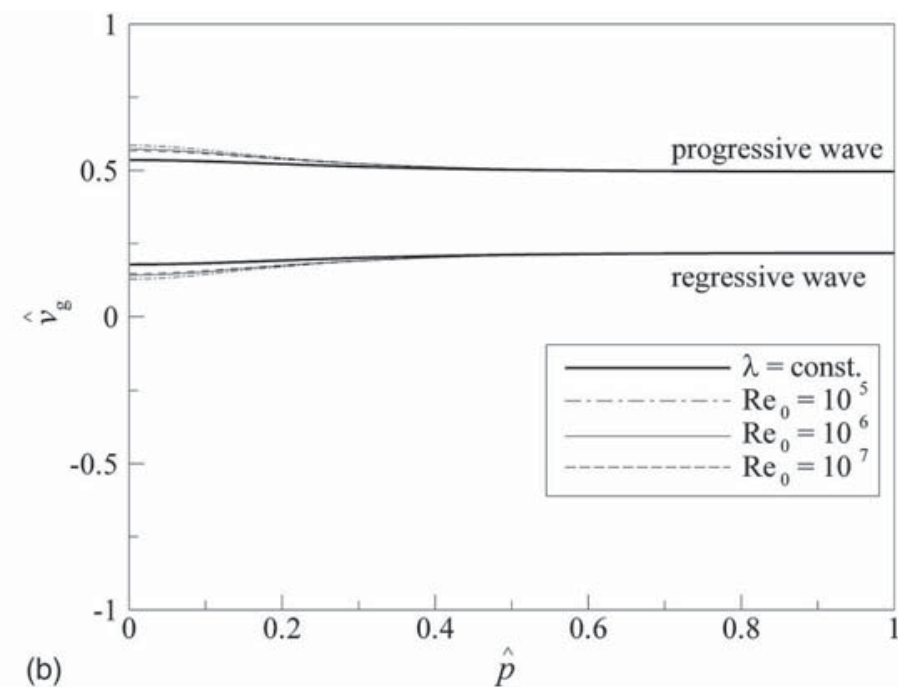

Fig. 1. Nondimensional group speed of the progressive and regressive waves for $\varepsilon_{0}=10^{-4}$ and various values of $R_{0}$; (a) $F_{0}=0.25$; (b) $F_{0}=2.5$ 


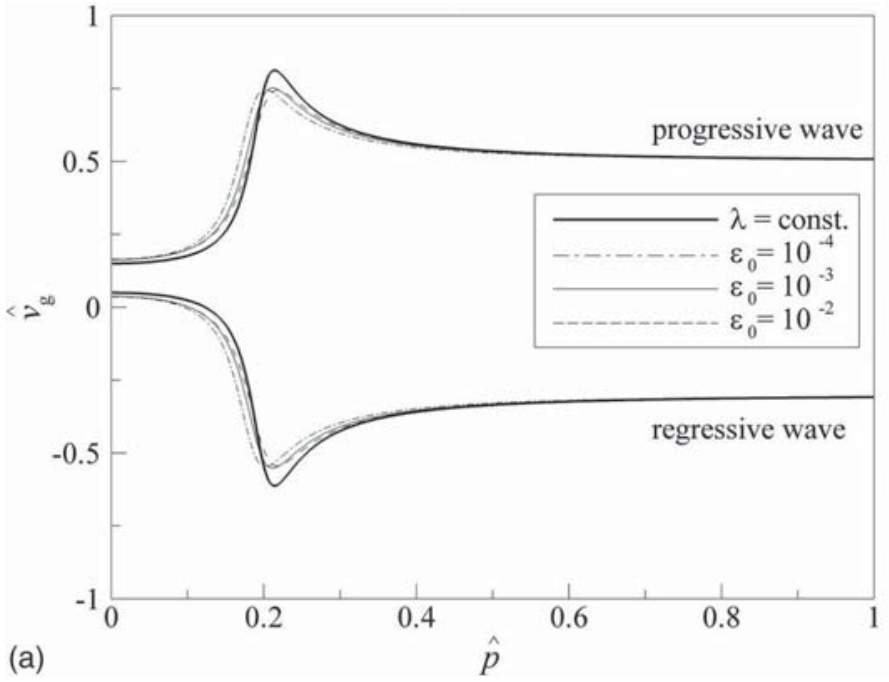

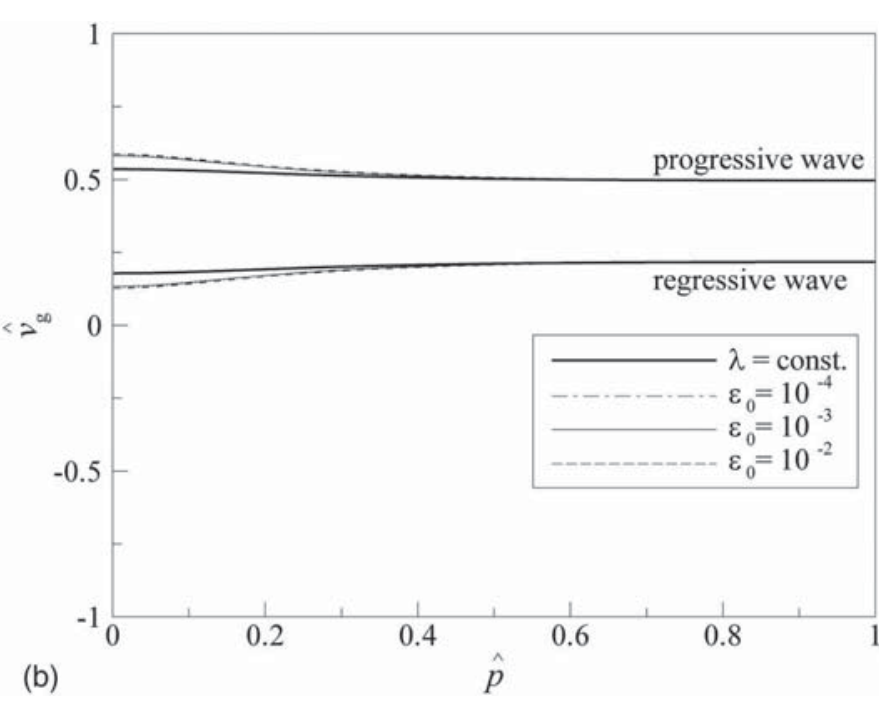

Fig. 2. Nondimensional group speed of progressive and regressive waves for $R_{0}=10^{5}$ and various values of $\varepsilon_{0}$; (a) $F_{0}=0.25$; (b) $F_{0}=2.5$

\section{References}

Di Cristo, C., Iervolino, M., and Vacca, A. (2012). "Green's function of the linearized Saint-Venant equations in laminar and turbulent flows." Acta Geophysica, 60(1), 173-190.

Di Cristo, C., Iervolino, M., Vacca, A., and Zanuttigh, B. (2009). "Roll waves prediction in dense granular flows." J. Hydrol., 377(1-2), 50-58.

Di Cristo, C., Iervolino, M., Vacca, A., and Zanuttigh, B. (2010) "Influence of relative roughness and Reynolds number on the roll-waves spatial evolution." J. Hydraul. Eng., 136(1), 24-33.

Engelund, F., and Wan, Z. (1984). "Instability of hyperconcentrated flow." J. Hydraul. Eng., 110(3), 219-233.

Forterre, Y., and Pouliquen, O. (2003). "Long-surface-wave instability in dense granular flows.” J. Fluid Mech., 486, 21-50.

Pascal, J. P. (2006). "Instability of power-law fluid flow down a porous incline." J. Non-Newtonian Fluid Mech., 133, 109-120.

Pascal, J. P., and D'Alessio, S. J. D. (2007). "Instability of power-law fluid flows down an incline subjected to wind stress." Appl. Math. Modell., 31, 1229-1248.

Rouse, H. (1959). Advanced mechanics of fluids, Wiley, New York.

Yen, B. C. (2002). "Open channel flow resistance." J. Hydraul. Eng., 128(1), 20-39.

\section{Closure to "Analysis of Dynamic Wave Model for Unsteady Flow in an Open Channel” by Maurizio Venutelli}

September 2011, Vol. 137, No. 9, pp. 1072-1078.

DOI: $10.1061 /(\mathrm{ASCE}) \mathrm{HY} .1943-7900.0000405$

\section{Maurizio Venutelli ${ }^{1}$}

${ }^{1}$ Dipartimento di Ingegneria Civile, Università di Pisa, Via Gabba 22, I-56126 Pisa, Italy. E-mail: m.venutelli@ing.unipi.it

The writer would like to thank the discussers for their interest in the original paper and for the opportunity to further clarify some aspects raised in the discussion.

The dynamic wave model examined in the original paper is based on the well-known continuity and momentum partial differential Saint-Venant, or shallow water (SW) equations. For these,
Eqs. (1) and (2) of the original paper, as well as basic assumptions, such as the fluid is a continuum, is incompressible, and is Newtonian, are automatically and tacitly included. More specific assumptions incorporated in the classic shallow water theory are recalled in the Technical Note. Therefore, fluids that possess non-Newtonian rheological properties, such as in the "References" of the discussion, are not represented by the set of SW equations.

To estimate the flow resistance $S_{f}$, ignoring the unsteadiness of the flow, Manning or Chézy formulas are commonly used. However, in these expressions, the factor of resistance, Manning's $n$, or Chézy $C$ is only dependent on the roughness and on the roughness and hydraulic radius or depth for very wide sections, respectively. Taking into account the variations of the velocity in the factor of flow resistance, the Darcy-Weisbach formula is suggested in the discussion. Thus, the Colebrook-White (CW) expression (Colebrook and White 1937; Colebrook 1939) that relates the Darcy's friction factor $\lambda$ to the roughness $\epsilon$, to the hydraulic radius $R$, and to the Reynolds number $\mathrm{R}$, is applied.

For instance, it is the writer's view that using the CW equation, which incorporates the R number, the so-called viscous SaintVenant equations (Gerbeau and Perhame 2001) are more appropriate as governing equations. Moreover, natural and artificial open channels are usually rough-surfaced and of large cross section corresponding to large $\mathrm{R}$ number, and turbulent flow is widely accepted. Excluding laboratory conditions, open channels laminar flow $(R \leq 500)$ is unusual, and the transition range (practically for $500<\mathrm{R} \leq 2,000$ ) is not as well defined as it is for pipe flow (Chow 1973). Therefore, the fully rough turbulent-flow limit of the CW expression can be applied to estimate the friction factor in open channels (White 2002).

However, accepting the CW relation in its universal form, the wide audience that this formula has received is probably because it was plotted by Moody (1944) in the preparation of his popular and useful Moody chart. In fact, because of its implicit nature, the CW equation must be solved by a trial-and-error procedure. Therefore, an initial guess value for the friction factor and a convergence criteria for the iterations must be chosen accurately. For these disadvantages of an implicit relationship, pointed out by Wood (1966), who recognized the necessity of an explicit expression, several approximations to the $\mathrm{CW}$ equation that are explicit in the friction factor have been proposed. 
In my opinion, these direct forms that involve a single step for computation of the friction factor could have been taken into consideration by the discussers. For example, the simple and accurate Haaland (1983) formula, with a maximum absolute error in $\lambda$ of $1.42 \%$, has the form

$$
\lambda=\left\{c_{1} \ln \left[\left(c_{2} \frac{\epsilon}{h}\right)^{1.11}+\frac{c_{3}}{\mathrm{R}}\right]\right\}^{-2}
$$

where $c_{1}=-1.8 / \ln (10) ; c_{2}=1 /(4 \times 3.7) ;$ and $c_{3}=6.9$. More accurate but more complex expressions are available. For a recent review of explicit CW approximations, see Genić et al. (2011). As can be seen in Eq. (1), the hypothesis of a very wide section, i.e., the depth $h$ is equivalent to the hydraulic radius $R$, has been assumed. Hence, the pipe diameter $D$, present in the original formulation, has been replaced by $4 h$.

For completeness, to reflect the effects of cross-sectional shape, according to the literature (Montes 1998; Sturm 2001) further modifications for computing the friction factor in open channel should be taken into account. Of these, Marchi (1961) introduces a shape coefficient $f$ in the form of a multiplier for the hydraulic radius (theoretically, $f=0.83$ for a very wide section). Kazemipour and Apelt $(1979,1982)$ suggested that the friction factor $\lambda$ obtained for circular pipe flows should be corrected as $\psi \lambda$, where the shape factor $\psi=\psi_{1} / \psi_{2}$. Expressions of $\psi_{1}$ and $\psi_{2}$ are given for the rectangular section as a function of the aspect ratio $\alpha=b / h$, where $b=$ channel width for approximately $1<\alpha<40$ by Sturm (2001) and Cheng et al. (2011) (for $\alpha=40, \psi \simeq 1.11$ ).

However, if the friction parameter $\eta=\lambda /(8 g)$ is a function of flow depth $h$ and of velocity $u$, the friction slope $S_{f}$ is given by Eq. (2) of the discussion, and the dispersion relation becomes

$$
\begin{aligned}
\omega= & \kappa u_{0} \pm \sqrt{\left[c^{2} \kappa^{2}-\frac{r^{2}}{4}\left(1+\frac{A}{2}\right)^{2}\right]+i \kappa r u_{0}\left(m-\frac{B}{2}\right)} \\
& -i \frac{r}{2}\left(1+\frac{A}{2}\right)
\end{aligned}
$$

where the coefficients $A$ and $B$ are defined by Eq. (3) of the discussion. Using for $\lambda$ the explicit Eq. (1), these coefficients result

$$
A=\frac{2 c_{1} c_{3} \lambda^{1 / 2}}{c_{3}+\mathrm{R}\left(c_{2} \epsilon_{0}\right)^{1.11}} \quad B=\frac{2 c_{1} \lambda^{1 / 2}\left(1.11 \times \mathrm{R}\left(c_{2} \epsilon_{0}\right)^{1.11}+c_{3}\right)}{c_{3}+\mathrm{R}\left(c_{2} \epsilon_{0}\right)^{1.11}}
$$

where $\epsilon_{0}=\epsilon / h$ is the relative roughness. Assuming $\mathrm{R}=10^{4 \div 8}$, the coefficients $A$ and $B$ are plotted for $10^{-6} \leq \epsilon_{0} \leq 10^{-1}$ in Figs. 1(a and b), respectively. From Eqs. (3), it is seen that for $\epsilon_{0} \rightarrow 0, A$, and $B \rightarrow 2 c_{1} \lambda^{1 / 2}(<0)$, while increasing $\epsilon_{0}, A \rightarrow 0$ more rapidly for higher $\mathrm{R}$ values and $B \rightarrow 2 \times 1.11 / \ln \left(\epsilon_{0} c_{2}\right)$ $(<0)$. Moreover, for $\epsilon_{0}=$ constant, $A$ and $B$ decrease as $\mathrm{R}$ decreases.

Because $B<0$, i.e., $\kappa r u_{0}(m-[B / 2])>0$, Eq. (2) can be rewritten in a more convenient form as Eq. (4) in the discussion. From this equation, the dimensionless group velocity $\hat{v}_{g}$, results:

$$
\hat{v}_{g}=b \mathrm{~F}_{o} \pm \frac{p b^{2}\left(2 \alpha_{1}+D_{f}^{2} \mathrm{~F}_{o}^{2}\left(m-\frac{B}{2}\right)^{2}\right)}{2 \sqrt{2}|\hat{z}| \sqrt{\alpha_{1}}}
$$

where

$$
\alpha_{1}=|\hat{z}|+p^{2} b^{2}-\frac{D_{f}^{2}}{4}\left(1+\frac{A}{2}\right)^{2}
$$

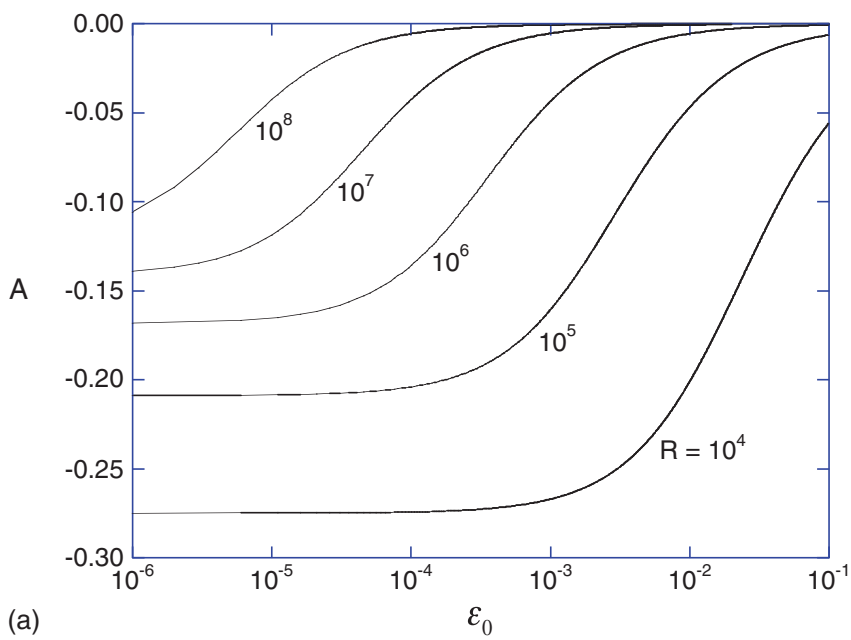

(a)

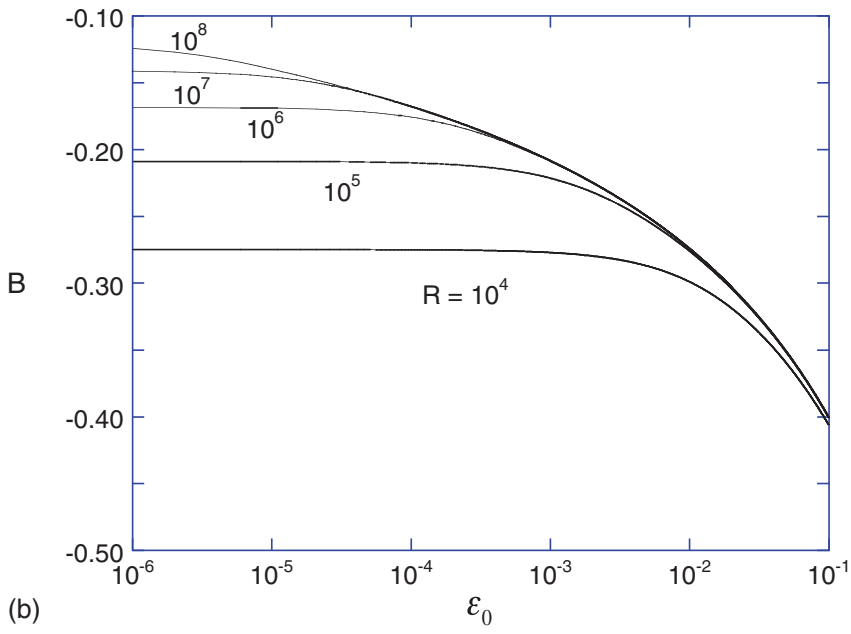

Fig. 1. Variations: (a) of coefficient $A$; (b) of coefficient $B$ with $\epsilon_{0}$ for various $R$ numbers

and

$$
|\hat{z}|=\sqrt{\left[p^{2} \mathrm{~b}^{2}-\frac{D_{f}^{2}}{4}\left(1+\frac{A}{2}\right)^{2}\right]^{2}+\left[p b \mathrm{~F}_{o} D_{f}\left(m-\frac{B}{2}\right)\right]^{2}}
$$

At this point, Eq. (4) and the expression of $|\hat{z}|$ are not in agreement with the analogous expressions in the discussion. Therefore, taking into account the variations of $\epsilon_{0}$ and of $\mathrm{R}$, only the progressive waves, the behavior of the group speed on the basis of Eq. (4) is presented. For $C_{r}=D_{f}=0.5$ and $\mathrm{F}_{o}=0.25$ and 2.5, and $m=1 / 2$; fixed $\epsilon_{0}=10^{-4}$; and assuming $\mathrm{R}=10^{4}$ and $10^{6}$ and fixed $R=10^{6}$; and assuming $\epsilon_{0}=10^{-2}$ and $10^{-6}$, the group speed $\hat{v}_{g}$ is represented, in the spectrum of dimensionless wave numbers $0 \leq \hat{p} \leq 0.5$ with the case for $\eta=$ constant, in Figs. 2(a and b), respectively.

As $p \rightarrow 0$, from Eq. (4), for progressive waves

$$
\hat{v}_{g} \rightarrow b \mathrm{~F}_{o}\left(1+\frac{\left(m-\frac{B}{2}\right)}{\left(1+\frac{A}{2}\right)}\right)
$$

is obtained, which corresponds to the value for the kinematic and diffusion models. Because $A$ and $B$ are less than zero, this value is greater than the value of 


$$
\hat{v}_{g}=\frac{3}{2} b \mathrm{~F}_{o}
$$

for $\eta=$ constant, and as previously noted because $A$ and $B$ decrease as $\mathrm{R}$ decreases, $\hat{v}_{g}$ increases as $\mathrm{R}$ decreases.

As $p \rightarrow 1$ (Nyquist limit), for progressive waves, $\hat{v}_{g}$ tends to a value less or greater than the gravity value, i.e., $b\left(\mathrm{~F}_{o}+1\right)$ for $\mathrm{F}_{o} \lessgtr 2$, respectively. Thus $\mathrm{F}_{o}=2$ (for $m=1 / 2$ ) is the threshold value for the change of the wave behavior.

From another point of view, $\mathrm{F}_{o}=2$, i.e., Vedernikov number $\mathbf{V}=1$, describes the condition of neutral stability. For $\mathrm{F}_{o} \lessgtr 2$ $(\mathbf{V} \lessgtr 1)$, the flow regime is hydrodynamically stable and unstable, respectively (Vedernikov 1945, 1946; Chow 1973). Using the well-known Manning formula $(m=2 / 3)$, the critical threshold value for the Froude number is $\mathrm{F}_{o}=1.5$. However, as noted by Whitham (1974), if $\mathbf{V}>1$, the flow is not necessarily chaotic and without structure. In favorable circumstances, it takes the form of the "roll-waves," with a periodic structure of discontinuous bores separated by smooth profiles.

For fixed $\epsilon_{0}$ [Fig. 2(a)], for $\mathrm{F}_{o}=0.25$ and up to $\mathrm{F}_{o}=2$, the group speed presents critical points (maximum or minimum) for
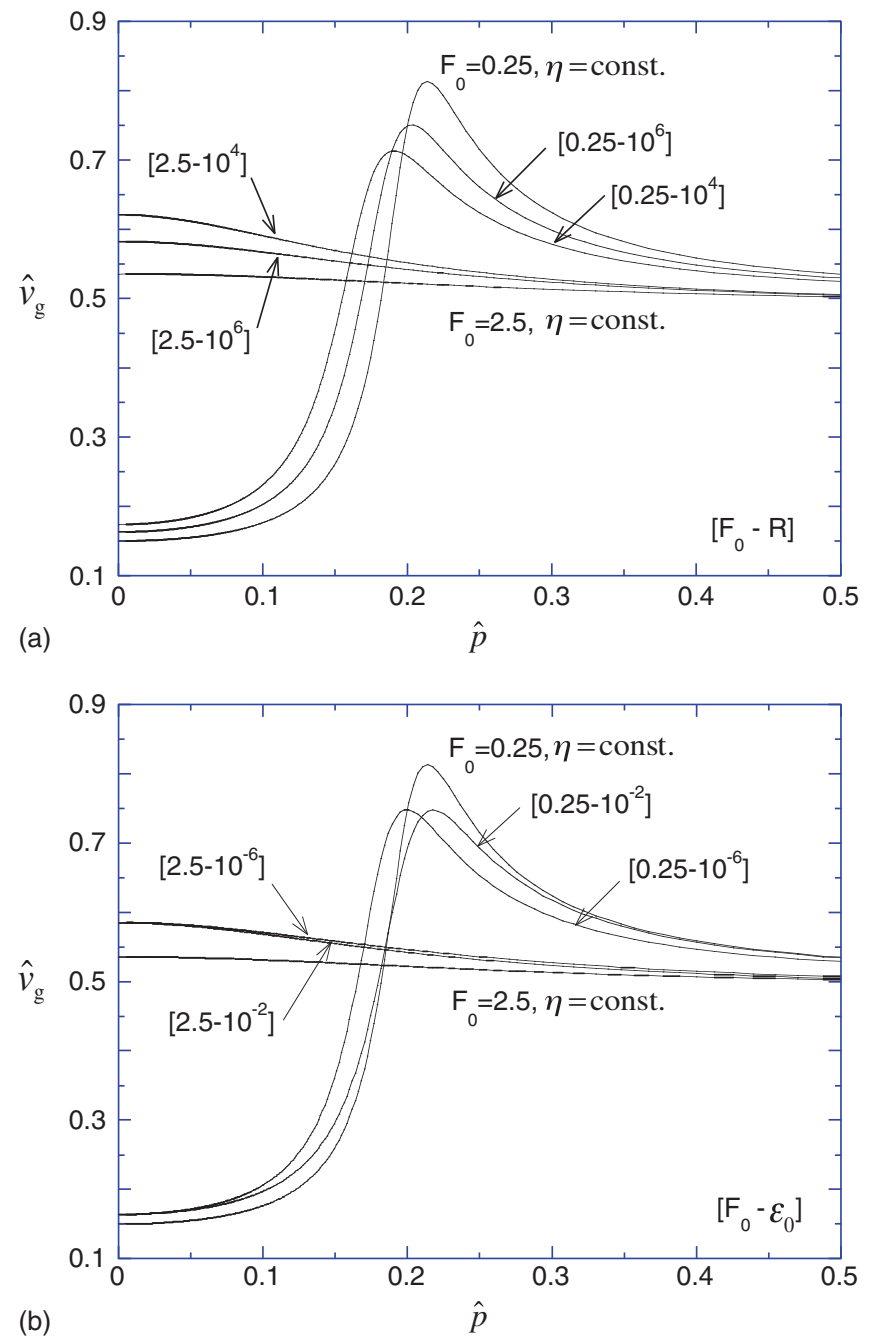

Fig. 2. Dimensionless group speed for progressive waves for $0 \leq \hat{p} \leq$ 0.5 and $C_{r}=D_{f}=0.5$ : (a) with $\mathrm{F}_{0}$ and $\mathrm{R}$ variables for $\epsilon_{0}=10^{-4}$; (b) with $F_{0}$ and $\epsilon_{0}$ variables for $R=10^{6}$ progressive and regressive waves, respectively. From Eq. (4), the corresponding abscissa $\hat{p}_{c}$ of these critical points result

$$
\hat{p}_{c}=\left(\mathrm{F}_{o}+1\right) \frac{D_{f}}{2 \pi C_{r}} \sqrt{\left(1+\frac{A}{2}\right)^{2}+\mathbb{C}}
$$

where

$$
\mathbb{C}=\frac{1}{6} \mathrm{~F}_{o}(B-1)\left(\mathrm{F}_{o}(B-1)-\beta\right)
$$

and

$$
\beta=\sqrt{3(2+A)^{2}+\mathrm{F}_{o}^{2}(B-1)^{2}}
$$

The critical group speed values $\hat{v}_{\mathrm{gc}}$ are given by

$\hat{v}_{\mathrm{gc}}=\frac{C_{r}}{\mathrm{~F}_{o}+1}\left(\mathrm{~F}_{o} \pm \frac{\left(2(\mathbb{C}+\sqrt{\mathbb{D}})+\mathrm{F}_{o}^{2}(1-B)^{2}\right) \sqrt{\left(1+\frac{A}{2}\right)^{2}+\mathbb{C}}}{2 \sqrt{2 \mathbb{D}(\mathbb{C}+\sqrt{\mathbb{D}})}}\right)$

where

$$
\mathbb{D}=\mathbb{C}^{2}+\left[\left(1+\frac{A}{2}\right)^{2}+\mathbb{C}\right] \mathrm{F}_{o}^{2}(1-B)^{2}
$$

As $\mathrm{R}$ decreases the values of $\hat{p}_{c}$ and $\hat{v}_{\mathrm{gc}}$ decrease. For $\mathrm{F}_{o}=2.5$ the group speed increases as $\mathrm{R}$ decreases, and as $\hat{p} \rightarrow 0$. For fixed $\mathrm{R}$ [Fig. 2(b)], for $\mathrm{F}_{o}=0.25$, as $\epsilon_{0}$ decreases the abscissa of the critical points $\hat{p}_{c}$ decreases, but the critical values of $\hat{v}_{\mathrm{gc}}$ are little influenced. For $\mathrm{F}_{o}=2.5$ the variations of $\epsilon_{0}$ do not seem to influence the group speed behavior.

From these results, it is concluded that in the spectrum of small and intermediate wave numbers, the variations of $R$ give rise to appreciable variations of the group speed for both subcritical and supercritical flow and, in particular as expected, at low R numbers, when viscosity is the dominant factor in the flow resistance. On the contrary, the variations of $\epsilon_{0}$ are influent only for subcritical flow.

\section{References}

Cheng, N.-S., Nguyen, H. T., Zhao, K., and Tang, X. (2011). "Evaluation of flow resistance in smooth rectangular open channels with modified Prandtl friction law." J. Hydraul. Eng., 137(4), 441-450.

Chow, V. T. (1973). Open-channel hydraulics, McGraw-Hill, Tokyo.

Colebrook, C. F. (1939). "Turbulent flow in pipes with particular reference to the transition region between the smooth and rough pipe laws." J. Inst. Civil Eng., 11(4), 133-156.

Colebrook, C. F., and White, C. M. (1937). "Experiments with fluid friction in roughened pipes.” Proc. R. Soc. Lond. A, 161(906), 367-381.

Genić, S., Arandjelović, I., Kolendić, P., Jarić, M., Budimir, N., and Genić, V. (2011). "A review of explicit approximations of Colebrook's equation.” FME Trans., 39(2), 67-71.

Gerbeau, J.-F., and Perthame, B. (2001). "Derivation of viscous saintvenant system for laminar shallow water; numerical validation." Discrete Contin. Dyn. Syst. B, 1(1), 89-102.

Haaland, S. E. (1983). "Simple and explicit formulas for the friction factor in turbulent pipe flow." J. Fluids Eng., 105(1), 89-90.

Kazemipour, A. K., and Apelt, C. J. (1979). "Shap effects on resistance to uniform flow in open channels." J. Hydraul. Res., 17(2), 129-147.

Kazemipour, A. K., and Apelt, C. J. (1982). "New data on shape effects in smooth rectangular channels." J. Hydraul. Eng., 20(3), 225-233.

Marchi, E. (1961). "Il moto uniforme delle correnti liquide nei condotti chiusi e aperti." L'Energia Elettrica, 38(5), 393-413 (in Italian). 
Montes, S. (1998). Hydraulics of open channel flow, ASCE, Reston, VA.

Moody, L. F. (1944). "Friction factors for pipe flow." Trans. ASME, 66(8), 671-684.

Sturm, T. W. (2001). Open channel hydraulics, McGraw-Hill, New York.

Vedernikov, V. V. (1945). "Conditions at the front of a translation wave disturbing a steady motion of a real fluid." Comptes Rendus (Doklady) de l'Académie des Sciences de l'URSS, 48(4), 239-242.

Vedernikov, V. V. (1946). "Characteristics features of a liquid flow in an open channel." Comptes Rendus (Doklady) de l'Académie des Sciences de l'URSS, 52(3), 207-210 (in Russian).

White, F. M. (2002). Fluid mechanics, 4th Ed., McGraw-Hill, New York. Whitham, G. B. (1974). Linear and nonlinear waves, Wiley, New York.

Wood, D. J. (1966). "An explicit friction factor relationship." Civil Eng., 36(12), 60-61.

\section{Discussion of "Energy Dissipation down a Stepped Spillway with Nonuniform Step Heights" by Stefan Felder and Hubert Chanson}

November 2011, Vol. 137, No. 11, pp. 1543-1548.

DOI: $10.1061 /($ ASCE)HY.1943-7900.0000455

\section{Masayuki Takahashi, A.M.ASCE${ }^{1}$; and}

\section{Iwao Ohtsu, M.ASCE ${ }^{2}$}

${ }^{1}$ Assistant Professor, Dept. of Civil Engineering, Nihon Univ., College of Science and Technology, Kanda-Surugadai 1-8, Chiyoda-ku, Tokyo 101-8308, Japan (corresponding author). E-mail: masayuki@civil.cst nihon-u.ac.jp

${ }^{2}$ Professor, Dept. of Civil Engineering, Nihon Univ., College of Science and Technology, Kanda-Surugadai 1-8, Chiyoda-ku, Tokyo 101-8308, Japan.

The authors investigated the residual energy down a stepped spillway for the nonuniform and uniform step heights. The discussers would like to comment on the analysis of the data for the residual energy and to present the residual energy of skimming flows in view of the aerated flow characteristics.

\section{Analysis of Data for Residual Energy down a Stepped Spillway}

On the basis of dimensional considerations, the functional relationship of the residual energy $H_{\text {res }}$ for $R \geq 1.2 \times 10^{5}$ (Takahashi et al. 2005) can be expressed as

$$
\frac{H_{\text {res }}}{d_{c}}=\mathrm{f}\left(\frac{h}{d_{c}}, \frac{\Delta z_{0}}{d_{c}}, \theta\right)
$$

Regarding the configurations $\mathrm{A}, \mathrm{B}$, and $\mathrm{C}$ for the skimming flow at the last step edge, $H_{\text {res }} / d_{c}$ can be given as

$$
\frac{H_{\text {res }}}{d_{c}}=\mathrm{f}\left(\frac{h}{d_{c}}, \frac{\Delta z_{0}}{d_{c}}, \theta, \text { config. A, B, C }\right)
$$

For $h / d_{c} \geq 0.5\left(d_{c} / h \leq 2\right)$ of the skimming flow with uniform step heights, the value of $H_{\text {res }} / d_{c}$ is independent of $h / d_{c}$ (Ohtsu et al. 2004), and Eq. (1) is expressed as

$$
\frac{H_{\text {res }}}{d_{c}}=\mathrm{f}\left(\frac{\Delta z_{0}}{d_{c}}, \theta\right)
$$

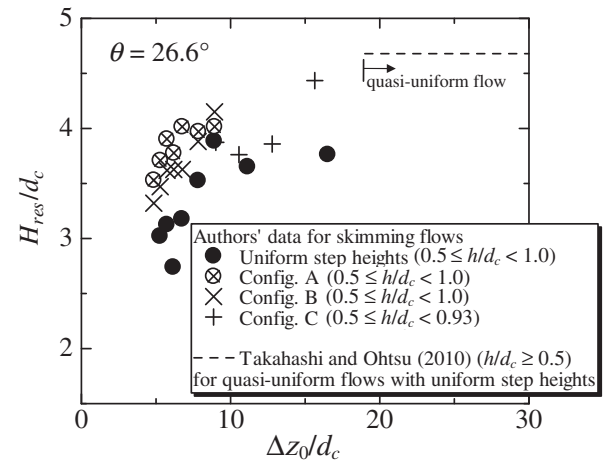

Fig. 1. Residual energy $H_{\text {res }} / d_{c}$ of skimming flows for $h / d_{c} \geq 0.5$

Also, for $h / d_{c} \geq 0.5$ of the skimming flow with nonuniform step heights, Eq. (2) may be rewritten as

$$
\frac{H_{\text {res }}}{d_{c}}=\mathrm{f}\left(\frac{\Delta z_{0}}{d_{c}}, \theta \text {, config. A, B, C }\right)
$$

Fig. 1 is obtained by arranging the authors' data in accordance with Eqs. (3) and (4). Here, the broken line in Fig. 1 shows the residual energy for $h / d_{c} \geq 0.5$ in the quasi-uniform skimming flow region with uniform step heights (Takahashi and Ohtsu 2010). As shown in Fig. $1, H_{\text {res }} / d_{c}$ increases with $\Delta z_{0} / d_{c}$ in the nonuniform flow region, and $H_{\text {res }} / d_{c}$ becomes constant for the quasiuniform flow region. For a given $\Delta z_{0} / d_{c}$, the values of $H_{\text {res }} / d_{c}$ for configurations $\mathrm{A}, \mathrm{B}$, and $\mathrm{C}$ are comparatively larger than those for uniform step heights. The scatter in the data of Fig. 4 in the original paper may mainly result from the effect of $\Delta z_{0} / d_{c}$ on $H_{\text {res }} / d_{c}$. However, further systematic experiments might be necessary to clarify the effect of $\Delta z_{0} / d_{c}, h / d_{c}$ (or $d_{c} / h$ ), $R$, and configurations on $H_{\text {res }} / d_{c}$ for a given $\theta\left(=26.6^{\circ}\right)$.

The rate of energy dissipation $\Delta H / H_{\max }\left[=1-\left(H_{\text {res }} / d_{c}\right) /\right.$ $\left.\left(\Delta z_{0} / d_{c}+3 / 2\right)\right]$ for $h / d_{c} \geq 0.5$ of the skimming flow at the last step edge can be expressed by Eq. (5) for uniform step heights and by Eq. (6) for nonuniform step heights:

$$
\frac{\Delta H}{H_{\max }}=\mathrm{f}\left(\frac{\Delta z_{0}}{d_{c}}, \theta\right)
$$

$$
\frac{\Delta H}{H_{\max }}=\mathrm{f}\left(\frac{\Delta z_{0}}{d_{c}}, \theta, \text { config. A, B, C }\right)
$$

Fig. 2 is obtained by arranging the authors' data in accordance with Eqs. (5) and (6), demonstrating that $\Delta H / H_{\max }$ increases

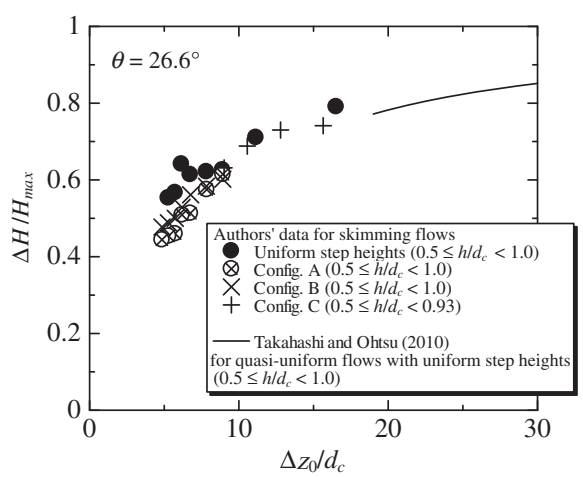

Fig. 2. Energy dissipation $\Delta H / H_{\max }$ of different step configurations for $0.5 \geq h / d_{c}$ of skimming flows 
with $\Delta z_{0} / d_{c}$ for all configurations including uniform step heights. In addition, the values of $\Delta H / H_{\max }$ for configurations $\mathrm{A}, \mathrm{B}$, and $\mathrm{C}$ are slightly smaller than those observed for uniform step heights.

\section{Residual Energy of Aerated Skimming Flows with Uniform Step Heights}

Considering the aerated flow characteristics, the residual energy (specific energy) $E$ of aerated skimming flows above the pseudobottom is (Ohtsu et al. 2004)

$$
E=\frac{\int_{0}^{Y_{90}}(\rho g y \cos \theta+p) V d y}{\int_{0}^{Y_{90}} \rho g V d y}+\frac{\int_{0}^{Y_{90}}\left(\frac{1}{2} \rho V^{3}\right) d y}{\int_{0}^{Y_{90}} \rho g V d y}
$$

where $p=\int_{y}^{Y_{90}} \rho g \cos \theta d y=$ pressure; and $\rho=(1-C) \rho_{w}=$ density of the aerated flow. Using the clear-water depth $d$ and the average clear-water velocity $U_{w}$, Eq. (7) can be expressed as (Ohtsu et al. 2005)

$$
E=C_{p} d \cos \theta+C_{v} \frac{U_{w}^{2}}{2 g}
$$

where

$$
\begin{gathered}
C_{p}=\frac{\int_{0}^{Y_{90}}(\rho g y \cos \theta+p) V d y}{\int_{0}^{d}\left(\rho_{w} g y \cos \theta+p_{w}\right) U_{w} d y} \\
=\frac{\int_{0}^{1}\left[(1-C) Y+\int_{Y}^{1}(1-C) d Y\right] U d Y}{\left(1-\int_{0}^{1} C d Y\right) \int_{0}^{1}(1-C) U d Y} \\
C_{v}=\frac{\int_{0}^{Y_{90}} \frac{1}{2} \rho V^{3} d y}{\rho_{w} q_{w} \frac{1}{2} U_{w}^{2}}=\frac{\left(1-\int_{0}^{1} C d Y\right)^{2} \int_{0}^{1}(1-C) U^{3} d Y}{\left[\int_{0}^{1}(1-C) U d Y\right]^{3}}
\end{gathered}
$$

with $p_{w}=\int_{y}^{d} \cdot \rho_{w} g \cos \theta d y$ as the clear-water pressure; $Y=y / Y_{90}$; and $U=V / V_{90}$. In Eq. (9), $C_{p}$ is the ratio of the potential energy flux plus the work done by the pressure for the aerated flow to that for the clear-water flow. The ratio of the kinetic energy flux for the aerated flow to that for the clear-water flow is $C_{v}$. According to Eqs. (9) and (10), the values of the correction coefficients $C_{p}$ and $C_{v}$ depend on the profiles of $C(Y)$ and $U(Y)$. For nonaerated flow, $C_{p}=1$ and $C_{v}=$ energy coefficient for single-phase flow (the Coriolis coefficient).

The authors described that the air concentration profile $C(Y)$ for all configurations including uniform step heights is approximated by Eq. (4) in the authors' paper using the depth-averaged air concentration $C_{m}$. For the uniform step heights in the quasi-uniform and nonuniform skimming flows, the velocity profile of aerated flows $U(Y)$ may be approximated with the $1 / N$ th power law as

$$
U=Y^{1 / N} \text { for } 0 \leq Y \leq 1
$$

For the quasi-uniform skimming flow with a uniform step height, the values of $C_{m}$ and $N$ can be obtained from the empirical equations for $C_{m}$ and $N$ as $C_{m}=0.42-0.49$ and $N=5.9-9.8$ for $\theta=26.6^{\circ}$ and $0.5 \leq h / d_{c} \leq 1.0$ (Takahashi and Ohtsu 2010). Thus, the profiles of $C(Y)$ and $U(Y)$ can be determined. Using Eqs. (9) and (10), the values of $C_{p}$ and $C_{v}$ are estimated as $C_{p}=1.22-1.35$ and $C_{v}=1.08-1.04$ for $\theta=26.6^{\circ}$ and $0.5 \leq h / d_{c} \leq 1.0$. In the nonuniform flow region for all configurations, if the magnitude and distribution of $C(Y)$ and $U(Y)$ are experimentally obtained, the values of $C_{p}$ and $C_{v}$ can be evaluated from Eqs. (9) and (10).
To determine the relationship between the residual energy (specific energy) of the aerated flow $E$ and the conventional residual energy from the clear-water depth $H_{\text {res }}$, the ratio of $E / H_{\text {res }}$ is obtained from Eq. (8) in this paper and from Eq. (5) in the original paper:

$$
\frac{E}{H_{\text {res }}}=\frac{C_{p} d \cos \theta+C_{v} \frac{U_{w}^{2}}{2 g}}{d \cos \theta+\frac{U_{w}^{2}}{2 g}}=\frac{C_{p}\left(\frac{d}{d_{c}}\right) \cos \theta+\frac{C_{v}}{2}\left(\frac{d}{d_{c}}\right)^{-2}}{\left(\frac{d}{d_{c}}\right) \cos \theta+\frac{1}{2}\left(\frac{d}{d_{c}}\right)^{-2}}
$$

For the quasi-uniform skimming flow with uniform step heights, the values of $E / H_{\text {res }}$ can be evaluated from Eq. (12) with the values of $C_{p}, C_{v}$, and $d / d_{c}=[f /(8 \sin \theta)]^{1 / 3}$ in which $f[=$ $\left.8\left(d / d_{c}\right)^{3} \sin \theta\right]$ is the friction factor and is given as $f=0.14$ for $\theta=26.6^{\circ}$ and $0.5 \leq h / d_{c} \leq 1.0$ (Takahashi and Ohtsu 2010). The ratio of $E$ to $H_{\text {res }}$ results in $E / H_{\text {res }}=1.09-1.06$ for $\theta=26.6^{\circ}$ and $0.5 \leq h / d_{c} \leq 1.0$, suggesting that the evaluated values of $E$ may be more precise than those obtained from the conventional residual energy $H_{\text {res }}$. For the nonuniform flow region, the values of $E / H_{\text {res }}$ for all configurations can be obtained from Eq. (12) with the values of $C_{p}, C_{v}$, and $d / d_{c}$.

\section{References}

Ohtsu, I., Yasuda, Y., and Takahashi, M. (2004). "Flow characteristics of skimming flows in stepped channels." J. Hydraul. Eng., 130(9), 860-869.

Ohtsu, I., Yasuda, Y., and Takahashi, M. (2005). "Energy head of aerated flows in stepped channels." Proc., 31 st IAHR Congress, IAHR, Madrid, Spain, 2890-2899.

Takahashi, M., and Ohtsu, I. (2010). "Effect of channel slope on aerated flow characteristics in stepped channels." Annu. J. Hydraul. Eng., 54, 1057-1062 (in Japanese).

Takahashi, M., Yasuda, Y., and Ohtsu, I. (2005). "Effect of Reynolds number on characteristics of skimming flows in stepped channels." Proc. 31st IAHR Congress, IAHR, Madrid, Spain, 2880-2889.

\section{Closure to "Energy Dissipation down a Stepped Spillway with Nonuniform Step Heights" by Stefan Felder and Hubert Chanson}

November 2011, Vol. 137, No. 11, pp. 1543-1548.

DOI: $10.1061 /(A S C E) H Y .1943-7900.0000455$

\section{Stefan Felder ${ }^{1}$ and Hubert Chanson ${ }^{2}$}

${ }^{1}$ School of Civil Engineering, The Univ. of Queensland, Brisbane QLD 4072, Australia.

${ }^{2}$ School of Civil Engineering, The Univ. of Queensland, Brisbane QLD 4072, Australia (corresponding author). E-mail: h.chanson@uq.edu.au

The writers thank the discussers for their comments. Herein they develop on the dimensional considerations and residual head data.

In skimming flows above prototype stepped spillways, two key features are the strong free-surface aeration and air-water flow turbulence (Chanson 2001). In any dimensional analysis, the relevant parameters include the fluid properties and physical constants, the chute geometry and inflow conditions, the air-water flow properties, and the geometry of the steps (Chanson and Gonzalez 2005; Felder and Chanson 2009). A number of recent studies emphasized that the concept of dynamic similarity and scale effects are 
closely linked with the selection of relevant characteristic air-water flow properties (Chanson 2009). A critical aspect is the selection of the relevant length scales. Most physical studies of stepped spillways including the discussion assumed implicitly that the vertical step height is the characteristic length scale. This selection is inadequate for a stepped spillway with nonuniform step heights because there is more than one step height in the original paper. Traditional results obtained on stepped chutes with uniform step height might become unsuitable.

In the original paper, the residual head at the measurement section was calculated as

$$
H_{\text {res }}=\cos \theta \int_{0}^{Y_{90}}(1-C) d y+\frac{\left[\int_{0}^{Y_{90}}(1-C) V d y\right]^{2}}{2 g\left[\int_{0}^{Y_{90}}(1-C) d y\right]^{2}}
$$

where $Y_{90}=$ characteristic depth where $C=0.90 ; C=$ void fraction; and $V=$ interfacial velocity. In Eq. (1), right side, the first term is the depth-averaged pressure head and the second term is the kinetic energy head. The velocity correction term was assumed unity and the pressure distribution was assumed hydrostatic.
The discussers pointed out nicely that the pressure gradient might differ locally from the hydrostatic pressure gradient because the streamlines might not be parallel to the average chute slope on a nonuniform stepped invert. There is, however, a lack of physical data in terms of pressure distributions to argue and to quantify the effect of the streamline curvature.

\section{References}

Chanson, H. (2001). The hydraulics of stepped chutes and spillways, Balkema, Lisse, Netherlands.

Chanson, H. (2009). "Turbulent air-water flows in hydraulic structures: Dynamic similarity and scale effects." Environ. Fluid Mech., 9(2), 125-142.

Chanson, H., and Gonzalez, C. A. (2005). "Physical modelling and scale effects of air-water flows on stepped spillways." J. Zhejiang Univ. Sci. A, 6A(3), 243-250.

Felder, S., and Chanson, H. (2009). "Turbulence, dynamic similarity and scale effects in high-velocity free-surface flows above a stepped chute." Exp. Fluids, 47(1), 1-18. 